\title{
Krishi-Mitra: Case Study of a User-centric ICT Solution for Semi-literate and Illiterate Farmers in India
}

\author{
Rajasee Rege \\ Interaction Designer \\ Human Computer Interaction Design \\ Indiana University, Bloomington, USA \\ rrege@umail.iu.edu
}

\author{
Shubhada Nagarkar \\ Lecturer \\ Department of Lib. \& Inf. Science \\ University of Pune, Pune India \\ shubha@unipune.ernet.in
}

\begin{abstract}
More than $70 \%$ of the Indian population resides in rural area. This non-English speaking population practices agriculture as the main livelihood. Although farmers in India possess deep knowledge about traditional agricultural practices, they often lack immediate, contextual and real time access to vital factual information such as the current market prices for specific produce at their local agro-market, seed procurement, pest management, real-time updates on weather conditions etc. We designed and tested "Krishi-Mitra", a user-centered ICT (Information and Communication Technology) solution that aims to revolutionize the rural farming communities in India by providing seamless access to vital agricultural information. We envisage "Krishi Mitra" as a user-centered information system with an easy to use, efficient, scalable, community oriented design that aims to promote professional growth of the rural farmers. The user interface of KrishiMitra is thoughtfully designed using audio- visual-textual cues and familiar high affordance metaphors that are easily understood not just by literate but also by the illiterate and semi-literate farmers. It supplements direct two-way interaction between farmers and agricultural experts, thus eliminating possible exploitation of farmers through deceitful intermediaries. To scaffold this design endeavor, we conducted rapid ethnographic research to uncover a deeper understanding of the information needs of rural farmers in two different districts in the State of Maharashtra in India. In this paper, we introduce the interface design of Krishi-Mitra realized through a conceptual prototype and discuss qualitative usability testing results of the User Interface of Krishi-Mitra conducted with five farmers in the Ahmadnagar district of Maharashtra in India. We believe that the findings and discussions from this case study will prove useful to interface designers and user researchers to inform and guide future work in this important area.
\end{abstract}

User interface, low literacy users, agriculture, information system, user-centered ICT, interaction design, usability testing, digital divide, audio-visual metaphors, interaction design, information design

\section{INTRODUCTION}

Designing an information system for rural Indian population is a challenging task. The challenge manifolds when the target group is illiterate. The rural Indian population faces multiple barriers like poverty, illiteracy, and diversity in geography, culture, and language, notion of "caste", apprehension towards adopting technology, ignorance, superstition, corruption and the lack of robust infrastructure. All of these grave issues are discussed at length in $[2,3,5,7,8,11,13,17,18$, $22,23,24,25,30]$.
Because the target population is so diverse, it is essential to take both a qualitative and quantitative research oriented approach in order to get a deeper understanding of the information needs of the user population. Design and implementation of human-centered ICT solutions that cater to the information needs of such a unique target group such as the rural farmers in India will provide them an opportunity to rise against corruption, exploitation and make more informed decisions in their profession. The current dissemination system in India is mostly paper based or through word of mouth. Farmers often incur heavy losses due to ignorance, lack of most recent agro based 
updates and their dependence on the informal intermediaries. Most of the rural population has never seen or heard of computers or advanced technologies. Most of the rural population cannot afford hi-end technologies and is quite apprehensive of utilizing or purchasing technologies due to lack of sufficient training or funds to purchase these devices. In [24] Parikh et. al. explain that there exists a huge difference in income, expenditure levels, and travel times between cities and villages. Travel is difficult, timeconsuming, tedious and cumbersome in rural areas.

In the past decade, India has displayed exponential rise in the usage of telecommunication systems. In joshi.et.al.[13], the authors mention that the current growth is primarily contributed through voice communication along with the rest of the utilities and applications staying un-leveraged and unexplored by the low literacy and illiterate population. Mobile phones and information kiosks have gained considerable acceptance in rural areas in India. However, their appropriation for disseminating contextual information to rural farmers is not yet realized on a large scale and only limited to design projects like eSagu, iShakti, Tamil Market, KioskNet, Digital Green and others [8, 18, $19,22,26,28,29]$. Leading IT and communication technology giants like Nokia, Infosys and Microsoft have also realized the importance of catering to the information needs of the rural populations in several parts of the world and are undertaking projects like Nokia Life Tools, specialized IT systems and Digital Green, etc. [11, 18, 19, 22].

Census data from year 2001 shows that $45 \%$ (468 million) people in India are illiterate and about $76 \%$ (771 million) people have not studied beyond the mandatory primary school. Census data for the year 1991 shows that English is the first language for only $0.02 \%$ of Indians and second and third language for $8 \%$ and $3 \%$ respectively. Parikh et al in [24] mention that using numbers in user interface can prove beneficial for low literacy rural population. In $[12,24]$, the authors also elaborate on how keyboards designed in English make text entry difficult for non English speaking population. Standardization of keyboard mappings for other languages has been limited and remains unrealized on a large basis. Even to those who are introduced to the world of mobile phones or kiosks often get confused in the cobweb of complex menus and confusing navigation. Many of the rural areas lack a robust infrastructure [17, 24, 27].

\section{KRISHI MITRA: USER INTERFACE}

After doing extensive literature review, we realized that there are very few attempts like Rangoli, Tamil
Market, Bhaav Puchiye and few others [2, 18, 19, $13,26]$ to design an information access system for illiterate rural farmers in India. We wanted to design a system which would be intuitive, extremely easy to use and highly appealing to illiterate farming population in rural India; one that would require least amount of training to use and support exploration and eliminate confusion or complication.

We conducted the research and design studies in the Maharashtra state of India due to our familiarity with the local language (Marathi) and geographic proximity to the target group. Prior to design exploration of Krishi-Mitra, we conducted rapid ethnographic research with a total of nearly 40 farmers in Sindhudurg and Pune district. We wanted to understand what kind of agricultural information do the farmers currently have access to, what are their information access practices and resources, and their level of familiarity with useful ICT technologies like computers, landline phones, mobile phones, the internet, etc.

More than $50 \%$ of the farmers (28 out of 40 ) owned a television set with only the national channels, namely Doordarshan 1 and 2 telecasted through dish TV antenna. The participants mentioned that they are aware of farming related advertisements and informational shows being aired on these national channels but they are often working on the field and seldom find time to watch these shows. Most farmers rely on crop management information provided by the owners of local retail stores that sell fertilizers, pesticides, seeds, and insecticides. Further, farmers rely heavily on traditional farming practices, such as the use of cattle and wooden ploughs, the use of organic fertilizers (cow dung, green waste from farm) for treating the farm [see figure 1]. Most of the farmers still use local wells to irrigate their crops. Typically, farmers gather informally every fortnight to discuss farming issues. However, farmers hardly obtain the latest information regarding advanced techniques in farming or tools available in the market.

The farmers grow a diversity of crops like paddy, legumes, chilli, lentils, cashew nuts in Sindhudurg district and crops like cabbage, carrots, wheat, corn, onion in Pune districts, each of which presents a distinct set of problems. To aid farmers in improving crop yield, the government has established co-operative societies through which it organizes exhibitions, symposiums, conferences, and during these events, information is provided to farmers regarding seed procurement, loans, soil nurture, marketing, agricultural methods, and fertilizers availability, among other things. These events are typically held in nearby towns, often requiring farmers to travel $2-3$ hours via public 
transportation. Farmers expressed the need for information regarding quick weather changing conditions, available fertilizers, insecticides and pesticides suitable for their crops based on their cost and sales.

Another important way that low-literate farmers receive agro-based information is through local newspapers like Agro-won but the illiterate farmers cannot access this e-information disseminated through the medium of the newspaper. Most of the farmers, typically sell their produce through middlemen. Based on this ethnographic research [figure 1], we gathered a rich set of design insights.
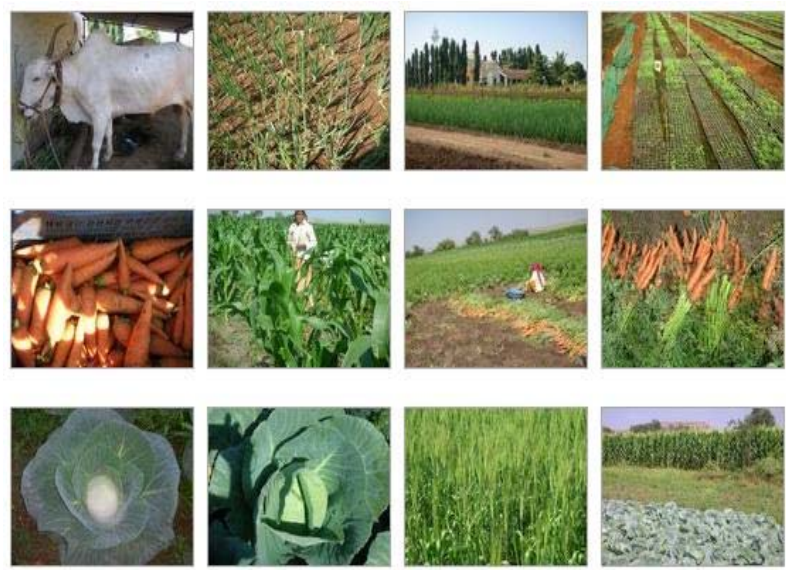

Figure 1: Snapshopt of from our ethnographic research in Maharashtra State with several farmers

We tried to design the User Interface of Krishi Mitra on the following research insights: The user interface should:

- be intuitive and easy to use

- eliminate dependency on mediators by providing contextual information through trusted sources

- provide range and depth of agricultural information

- $\quad$ support two way interaction between farmers and agricultural experts
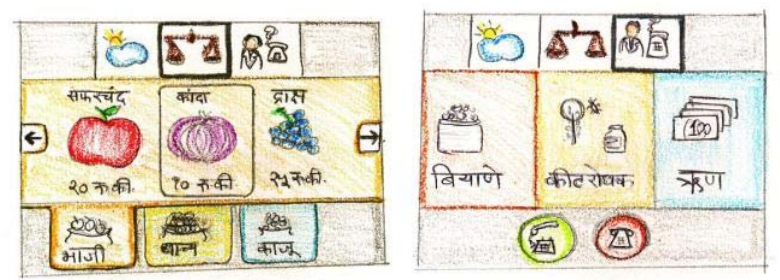

Figure 2: Design exploration of the Krishi-Mitra UI.

\subsection{The Hi fidelity Prototype of Krishi-Mitra}

After some initial design explorations using paper prototypes, the high fidelity prototype was built using Microsoft PowerPoint 2003 and the visual design was created using Adobe PhotoshopCS4. Voice-over for each of the icons was pre-recorded using Audacity open source software and embedded into the PowerPoint prototype.

While designing the Krishi-Mitra concept system, our major assumption was to provide information through trusted resource such as agricultural experts appointed by government for different local areas. Also, the interface should be scalable on an information kiosk as well as a GUI based mobile phone for facilitating both collective and individual utilization.

The user interface of Krishi-Mitra relies on audio visual cues to inform the current state, navigation and information display on the screen. Each of the buttons is designed to be a large clickable area with a large icon to reduce the room for error by clicking on the wrong button. The visual metaphors used in the interface were carefully designed based on prior contextual ethnographic research that we conducted earlier. Insights from the Rangoli project [13] suggest that colors and icons could very well work as navigation, however supplementing it with text helps in reducing errors, particularly for users with some literacy. Their study also showed that even people with low literacy memorize text as visual patterns and start recognizing them. We used this insight to guide our design of KrishiMitra. Easy to understand icons like clouds and sun for weather-updates, bag of seeds for seed procurement, icon of "pest-infected crop " for pest management, a measuring balance for market prices and so on were chosen for the design. The main navigation of Krishi-Mitra consists of three major options: to get information about weatherupdates, to get information on agricultural practices from local agricultural experts and to get information about current market prices of locally grown crops from the local agro-based markets. The main global navigation is always displayed at the top. The user is able to choose between any of these options simply by clicking on that option. Each of the options is provided with a voice over in the Marathi language to assist the farmer navigate through the system and seek the desired information. We decided to use visual metaphors along with dispensing information through audio feedback to reduce errors often encountered in purely audio systems [26] and to enhance reorientation of the current state of the user interface if the user has missed out on some audio feedback. 


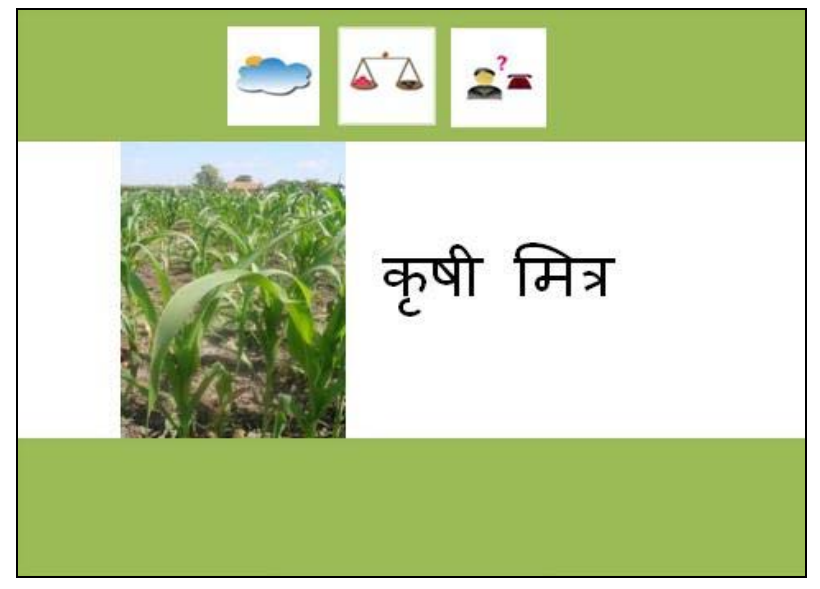

Figure 3: Welcome screen of Krishi Mitra

The screen [figure 3] is the welcome screen of Krishi-Mitra. On the welcome screen, the farmer has three options to choose from: weather-updates, market price updates, and speaking to an agricultural expert through a toll free number. As soon as the welcome screen launches, and the farmer hears an audio recording that tells the farmer of the available information choices. The farmer has to click on any of these icons to access that information.

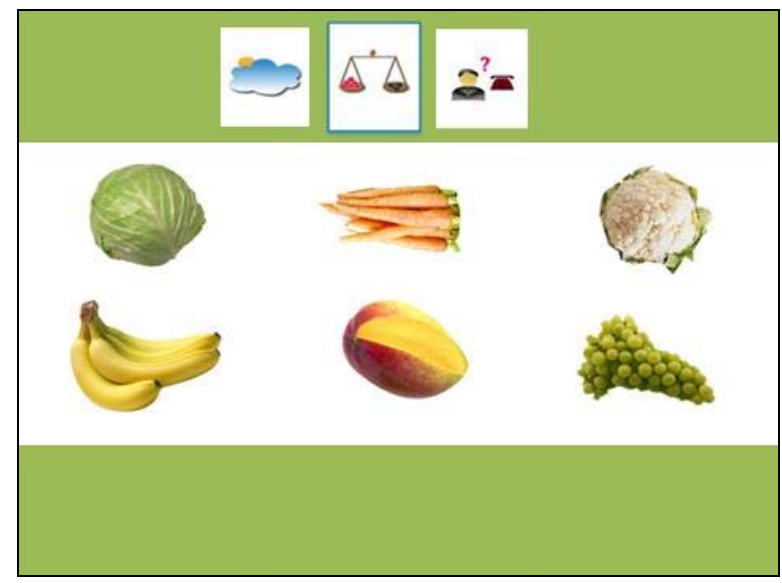

Figure 4: Screen to view market prices

This screen [figure 4] helps the farmers to select locally produced items and check their market prices in the local agro markets. As the farmer clicks on each item, the market price for that item in announced in Marathi, through the voice-over. At a time, only one voice over plays per selection. The items displayed were contextual to the region.

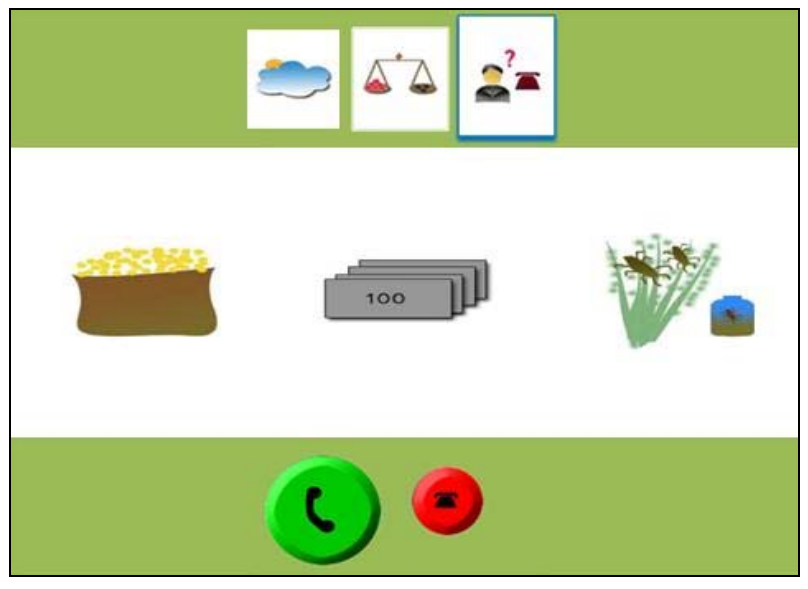

Figure 5: Screen to speak to agricultural experts

The screen [figure 5] enables the farmer to choose a question type and speak to an agricultural expert simply by clicking the green button with "open receiver icon" and he can cancel the call anytime by clicking the red button.

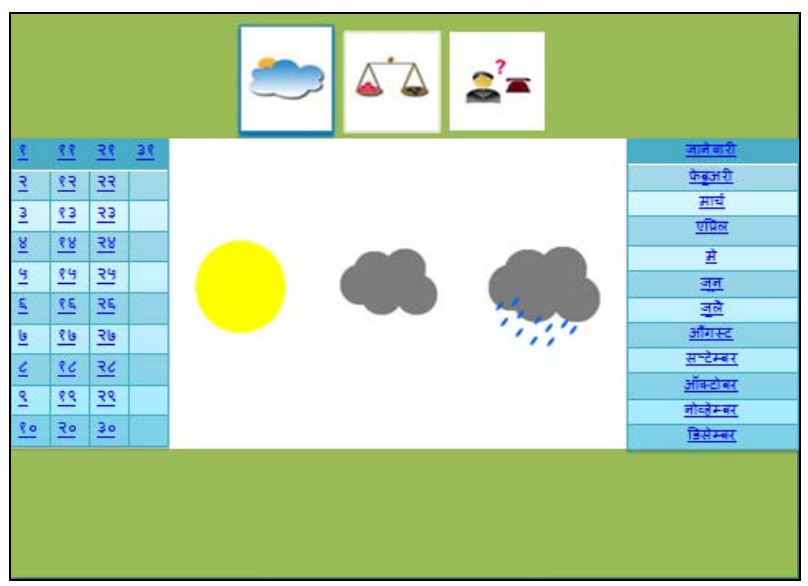

Figure 6: Screen to view weather updates

In the above screen [figure 6] the farmer can click on the sun icon to hear the maximum and minimum temperature by clicking on the cloud, humidity information is heard and the rainfall button will give information on rainfall. This information will be for the current day and current week. If the farmer wishes to learn about the weather updates of a different month, he can choose the month and date and click on the icons in the center to get those updates

\section{QUALITATIVE USABILITY STUDY}

We conducted formative evaluation [21] of the Krishi-Mitra hi fidelity prototype with five participants in Ahmadnagar district in Maharashtra State of India. We used a demographic questionnaire and a debriefing questionnaire to collect the participant information and their thoughts on the concept system after conducting 
the study. Small tasks were given to retrieve agricultural information using Krishi-Mitra. We took inspiration from the IDEO s $\mathrm{HCl}$ Design Tool kit [9] to aid our study. The goal of this qualitative usability study was to gauge whether the target group would be comfortable with the "point and click interaction. Through this formative evaluation we also intended to understand whether an audiovisual metaphor-based system would be easier to use and intuitive for illiterate and low-literate non English speaking rural farmers. The insights generated from this Formative study would help us improvise the design of Krishi-Mitra and influence its design directions in future.

\subsection{Participant Profiles}

Four of the participants were male farmers and one was female. All were small-scale farmers owning a farmland between $5-10$ acres. The four male participants were semi-illiterate (studied up to 6th 8th grade), the female participant was illiterate and their lives are far removed from the English language or technologies like computers, the internet. The male participants were familiar with the use of the mobile phones. They could dial using the keypad. All of them are dependent on a local shop keeper for making decisions about purchasing of pesticides, fungicide and fertilizers. The participants mentioned that this reliance on the local shop keepers has often led them into making incorrect decisions about purchasing seeds or selling their produce or even managing the pests. The participants also bank a lot on their traditional knowledge of farming to manage their farms.

\subsection{Methodology}

We ran the Krishi-Mitra prototype on a 15 inch laptop using an external mouse. At the beginning of the study, each of the participants was given an inperson demo of how to use a mouse with the laptop in order to understand the click interaction.

From the very beginning, the participants were clearly apprehensive of using a technology and performing a task they had never seen or heard of in their lives. They were simply worried because they feared that they would break it, if they used incorrectly. This concern was amplified with the illiterate participant. The participants required constant reassuring that nothing they did would be wrong or right and that we are testing the system and not the participants themselves. The participants often tried to touch the laptop screen in their attempt to select an option. These multiple attempts lead us to believe that the target group would be more comfortable using a touch screen interaction rather than a point and click interaction while using an audio-visual based user interface to access information.
After a few timid attempts, the participants suggested that they would prefer to "touch the options they would like to choose by pointing their finger to it rather than using the mouse to make a selection. Surprisingly, this request was consistent from all of the five participants. We complied with their request and conducted the rest of the study accordingly where the participants would touch the screen and the researcher would use the mouse to navigate through the system.

\subsubsection{Scenario based testing}

Following small tasks were given to the participants;

(i) Find out the recent market rate of cabbage in nearby market.

(ii) Seek an expert advice regarding the purchasing of seed

(iii) Find out information about tomorrows weather conditions

\subsection{Findings}

\subsubsection{Time required}

Each participant took about a total of 15-20 minutes to perform all of the above scenarios.

\subsubsection{Use of Icons}

By the end of the third scenario, all the participants got comfortable with the iconography and instantly identified most of them. The participants were initially confused and took few extra seconds to recognize or understand the "agricultural expert icon" and the "loans and schemes icon. Participants suggested that:

- Using a more intuitive icon like a telephone to indicate that they have an option for calling, instead of the complicated icon. The question mark icon was intuitive to the low literacy participants; but it did not appeal to the illiterate participants.

- The icon for bag of seeds could also be improvised to look like a huge sack of seeds rather than a small bag of seeds.

- They would prefer two separate icons for loans and for agricultural schemes introduced by the government.

- They would appreciate just a one click away mechanism to talk to an expert rather than choosing their type of question first. They suggested this, because they believe they would want to ask different types of questions in one long call instead of making separate calls to different experts.

\subsubsection{Positive feedback}

Participants enjoyed and applauded the icon and audio based system for its intuitiveness and visual appearance. They called it extremely simple and quick and moreover very useful for their profession. 
They appreciated the market prices and the produce items were very contextual to their region and the voice over was pleasant on the ears and easily understood. Three of the participants who owned a mobile phone suggested that they would also like to see such a system accessible through a mobile phone. The participants quipped that it was fun to play around and use the colourful text free system that required less thought and effort from their side and did more work on its own to get the desired information. They said that they would advocate the implementation of similar such services in their local area, if available freely or at considerably low-price.

\subsubsection{Trusted sources of information}

They participants proposed that the information through such a system be provided from trusted sources like a government organization or a trusted network of agricultural experts to ensure accuracy and most recent updates and eliminate chances of swindling from deceitful intermediaries. We came across several internet resources $[1,4,10,11,14$, $15,16,20]$ owned by government as well as private organizations willing to provide the information through the online platform.

Of particular concern was the weather screen. Although the low literacy participants could identify the months and dates and interact with it comfortably to fetch information on weather conditions, the illiterate participants were absolutely unable to recognize the months or dates. They however simply clicked on the sun and cloud icons and were glad to receive the current day's and the current week's weather update.

\section{REDESIGNING KRISHI-MITRA}

Based on the participant's feedback we received from the Qualitative usability testing, we redesigned the Krishi-Mitra interface screen to cater to their well noted suggestions and comments.

\subsection{Market prices}

The market prices screen was kept intact since it was the easiest to use and intuitive screen. The agricultural experts screen was changed to a simple call and cancel call button to serve as the simplest aid for the participants to make a call to the toll free number successfully.

\subsection{Weather}

The weather screen was redesigned to display simply the Sun, Cloud and Rainfall icon to provide an audio feedback on current day's and current week's updates on weather.

\subsection{Call to expert}

Additionally, a call button was added to the weather screen to fetch updates on future weather forecasts in the upcoming months through a toll free phone call.

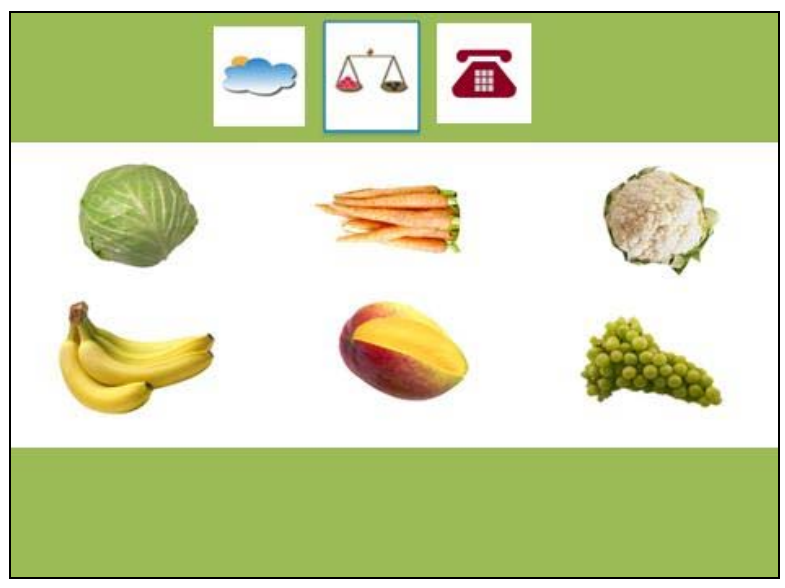

Figure 7: Redesigned Screen to view market prices

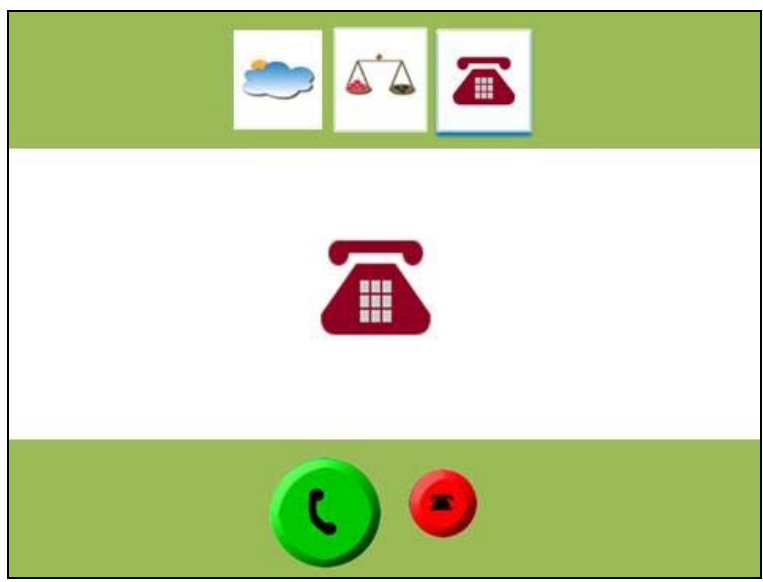

Figure 8: Redesigned Screen to make toll free call to an agricultural expert

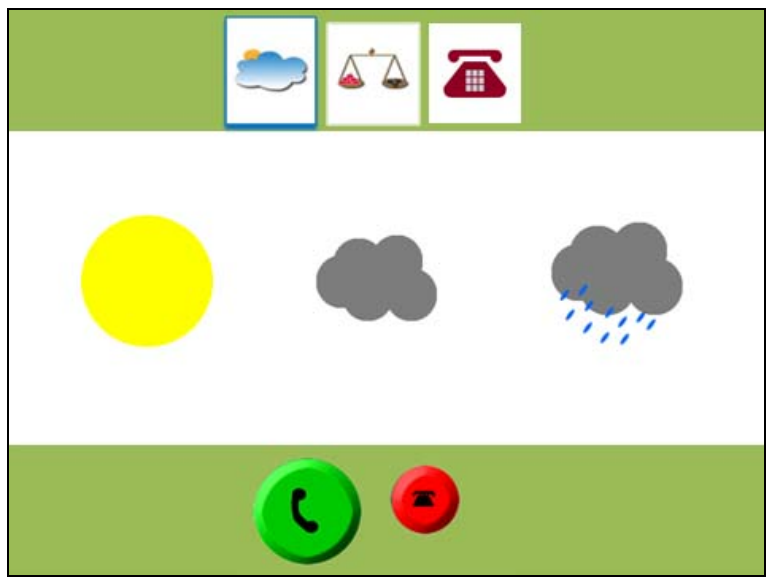

Figure 9: Redesigned Screen to check weather updates 


\section{CONCLUSION}

This study has given us two major design directions: firstly, to explore and compare touch screen interactions vs. point and click interactions for audio visual interfaces and secondly, to design such a system on a moderately to low price mobile phone with a much smaller screen real estate. In future, we would encourage fellow interface designers to explore these design directions while designing for non English speaking low literacy or illiterate target populations. We also believe that user interfaces that are purely based on icons and audio visual feedback are easily scalable across different regional areas across a multi cultural and diverse country like India. We would encourage and solicit for collaboration on similar projects targeted for the illiterate rural farming population to assist them in their noble profession and support their information needs.

\section{ACKNOWLEDGMENTS}

We would like to acknowledge Mr. and Mrs. Muley to assist us in conducting the Krishi-Mitra testing in Ahmednagar. Also we are thankful to all the farmers who participated in the usability testing of Krishi-Mitra. We would also like to thank Eli Blevis, Erik Stolterman, and Martin Siegel from Indiana University for their endless support and guidance during the course of the project. We are thankful to Asha Umarani from University of Pune for her guidance in documentation.

\section{REFERENCES}

1. aAqua Agriservice Website, Retrieved on October 12th 2009 from

http://aaqua.persistent.co.in

2. Agarwal, S., Kumar, A., Nanavati, A. A., and Rajput, N. 2008. VoiKiosk: increasing reachability of kiosks in developing regions. In Proceeding of the 17th international Conference on World Wide Web (Beijing, China, April 21 - 25, 2008). WWW '08. ACM, New York, NY, 1123-1124.

3. Bahuman, A., Bahuman, C., Baru, M., Duttagupta,S., and Ramamritham, K. 2007. Developmental informatics at IIT Bombay. SIGMOD Rec. 36, 1 (Mar.2007), 47-53.

4. Directorate of Marketing \& Inspection (DMI), Ministry of Agriculture, Government of India Website, Retrieved on 10th December 2009 from http://www.agmarknet.nic.in/

5. Gandhi, R., Veeraraghavan R., Toyama K., Wang R., Green Foundation, (2007). Digital
Green. Microsoft Research India. Retrieved on 27th October 2007 from http://digitalgreen.org/

6. Gaver, W. W. Auditory icons: Using sound in computer interfaces. Human-Computer Interaction, 2. (1989)

7. Grisedale, S., Graves, M and Grünsteidl, A. Designing a graphical user interface for healthcare workers in rural India, Proceedings of the SIGCHI conference on Human factors in computing systems, March 22-27, 1997, Atlanta, Georgia, United States

8. Guo, S., Falaki, M. H., Oliver, E. A., Ur Rahman, S., Seth, A., Zaharia, M. A., and Keshav, S. 2007. Very low-cost internet access using KioskNet. SIGCOMM Comput. Commun. Rev. 37, 5 (Oct. 2007), 95-100.

9. Human Centered Design Toolkit, IDEO, Retrieved on October 2nd, 2008 from https://client.ideo.com/hcdtoolkit/India

10. Development Gateway Website, Retrieved on December 1st 2009 from http://www.indg.in

11. Infosys, India., Infosys empowers farmers, February 2008, Retrieved on 16th October 2008 from

http://www.infosys.com/newsroom/pressreleas es/2008/infosy s-empowers-farmers.asp

12. Joshi, A., Ganu, A., Chand, A., Parmar, V., and Mathur, G.2004. Keylekh: a keyboard for text entry in indic scripts. In $\mathrm{CHI}$ '04 Extended Abstracts on Human Factors in Computing Systems (Vienna, Austria, April 24 - 29, 2004). CHI '04. ACM, New York, NY, 928-942.

13. Joshi, A., Welankar, N., BL, N., Kanitkar, K., and Sheikh, R. 2008. Rangoli: a visual phonebook for low-literate users. In Proceedings of the 10th international Conference on Human Computer interaction with Mobile Devices and Services(Amsterdam, The Netherlands, September 02 - 05, 2008). MobileHCl '08. ACM, New York, NY, 217-223. DOI=http://doi.acm.org/10.1145/1409240.1409 264

14. Krishi Sewa Website Retrieved on Novembers 19th 2009 from http://www.krishisewa.com/

15. Krishi Vigyaan Kendra Website Retrieved on October $9^{\text {th }} 2009$ from http://www.kvkbaramati.com/

16. Krishi World Website Retrieved on November 10th 2009 from http://www.krishiworld.com/ 
17. Lalmas, M., Bhat, R., Frank, M., Frohlich, D., and Jones, M. 2007. Bridging the digital divide: understanding information access practices in an indian village community. In Proceedings of the 30th Annual international ACM SIGIR Conference on Research and Development in information Retrieval (Amsterdam, The Netherlands, July 23 - 27, 2007). SIGIR '07. ACM, New York, NY, 741-742. DOI= http://doi.acm.org/10.1145/1277741.1277886

18. Medhi, I., Prasad, A., Toyama, K. Optimal audio-visual representations for illiterate users of computers. In Proc.WWW 2007, (2007), 873-882.

19. Medhi, I., Sagar A., and Toyama K. Text-Free User Interfaces for Illiterate and Semi-Literate Users. International Conference on Information and Communication Technologies and Development (Berkeley, USA), May 2006.

20. National Bank for Agriculture and Rural Development Website, Retrieved on December 1st 2009 from http://www.nabard.org/

21. Nielson, J. Why You Only Need to Test with 5 Users. Retrieved on August 1st 2009 from http://www.useit.com/alertbox/20000319.html

22. Nokia Press Release., Inform, Involve, Empower - Nokia's service mantra for emerging markets with Nokia Life Tools November 04, 2008, Retrieved on 20th November 2008 from http://www.nokia.com/A4136001?newsid=1266 168

23. Panchard, J., Rao, S., Sheshshayee, M. S., Papadimitratos, P., Kumar, S., and Hubaux, J. (2008). Wireless sensor networking for rain-fed farming decision support. In Proc. of the Second ACM SIGCOMM Workshop on Networked Systems For Developing Regions, 31-36.

24. Parikh, T. S. and Lazowska, E. D. 2006. Designing an architecture for delivering mobile information services to the rural developing world. In Proceedings of the 15th international Conference on World Wide Web (Edinburgh, Scotland, May 23 - 26, 2006). WWW '06. ACM, New York, NY, 791-800. DOI= http://doi.acm.org/10.1145/1135777.1135897

25. Patel, S., Bataveljic, O., Lisboa, P. J., Hawkins, C., and Rajan, R. (2006). iShakti--Crossing the Digital Divide in Rural India. In Proc. of the 2006 IEEE/WIC/ACM international Conference on Web intelligence, 1061-1065

26. Plauché, M., Prabaker, M. Tamil market: A spoken dialog system for rural India. In CHI Extended Abstracts 2006, (2006), 1619-1624.

27. Ramachandran, D., Kam, M., Chiu, J., Canny, J., and Frankel, J. F. 2007. Social dynamics of early stage co-design in developing regions. In Proceedings of the SIGCHI Conference on Human Factors in Computing Systems (San Jose, California, USA, April 28 - May 03, 2007). CHI '07. ACM, New York, NY, 1087-1096

28. Reddy, P. K., Ramaraju, G. V., and Reddy, G. S. 2007. eSagu ${ }^{\mathrm{TM}}$ : a data warehouse enabled personalized agricultural advisory system. In Proceedings of the 2007 ACM SIGMOD international Conference on Management of Data (Beijing, China, June 11 - 14, 2007). SIGMOD '07. ACM, New York, NY, 910-914.

29. Ratnam, B. V., Reddy P.K., and Reddy, G. S. eSagu: An IT based personalized agricultural extension system prototype - analysis of 51 Farmers case studies International Journal of Education and Development using Information

30. and Communication Technology (IJEDICT), 2005, Vol. 2, Issue1, pp. 79-94

31. Shiva, V., Jafri, A. H., Emani, A., Pande, M., Seeds of Suicide: The ecological and human costs of globalization of agriculture, retrieved on 5th January 2009 from http://www.navdanya.org/ 